\title{
Successful treatment of rectovaginal fistula and rectal stenosis due to perianal Crohn's disease by dual-port laparoscopic abdominoperineal resection: a report of two cases
}

Fumihiko Matsuzawa, Shigenori Homma, Tadashi Yoshida, Susumu Shibasaki, Nozomi Minagawa, Tatsushi Shimokuni, Hideyasu Sakihama, Hideki Kawamura, Norihiko Takahashi and Akinobu Taketomi

\begin{abstract}
Background: The incidence of rectovaginal fistula in women with Crohn's disease has been reported to be 3-10\%. Although rectovaginal fistulas can be managed medically and surgically, they have high rates of recurrence and complications. Rectal stenosis is another condition that occurs due to perianal Crohn's disease. A novel, minimally invasive procedure, dual-port laparoscopic abdominoperineal resection using a multichannel port, has been shown effective in patients with lower rectal cancer and patients with medically uncontrolled ulcerative colitis. This report describes the use of the same method for two patients with Crohn's disease-related rectovaginal fistula and rectal stenosis.
\end{abstract}

Case presentation: The first patient, a 22-year-old woman, was diagnosed with rectovaginal fistula and rectal stenosis due to perianal Crohn's disease 2 years earlier. Induction therapy with infliximab and endoscopic balloon dilatation did not improve her symptoms. The second patient, a 33-year-old woman, was also diagnosed with rectovaginal fistula and rectal stenosis due to perianal Crohn's disease, and medical treatment was also unsuccessful. Both patients underwent dual-port laparoscopic abdominoperineal resection using a multichannel port, with no perioperative and postoperative complications.

Conclusion: These findings show that this reduced port method can be used to successfully treat patients with Crohn's disease-associated rectovaginal fistula and rectal stenosis.

Keywords: Rectovaginal fistula, Rectal stenosis, Perianal Crohn's disease, Reduced port surgery, Dual-port laparoscopic abdominoperineal resection

Abbreviations: CD, Crohn's disease; RVF, rectovaginal fistulas.

\footnotetext{
*Correspondence: homma.s@nifty.com

Department of Gastroenterological Surgery I, Hokkaido University Graduate

School of Medicine, North 15, West 7, Kita-Ku, Sapporo, Hokkaido 060-8638,

Japan
} 


\section{Background}

Fistulas are abnormal tracts arising from mucosal ulcerations in the gastrointestinal tract that have progressed to penetrate other structures [1]. The cumulative incidence of fistulas in patients with Crohn's disease (CD) has been reported to be $33 \%$ after 10 years and $50 \%$ after 20 years, with $83 \%$ of all fistula episodes requiring surgery [2]. The incidence of rectovaginal fistulas (RVF) in women with $\mathrm{CD}$ has been reported to be approximately 3-10\%. Although medical and surgical management techniques have been described, these fistulas are difficult to manage because of their high rates of recurrence and complications. In addition to RVF, women with CD can also experience rectal stenosis, a major complication that is also difficult to manage [3].

We have described the successful use of laparoscopically assisted anterior resection, using a single incision and one additional port, for patients with rectal cancer [4]. Based on this technique, we have developed a novel, minimally invasive procedure, dual-port laparoscopic abdominoperineal resection using a multichannel port, and shown its effectiveness in patients with lower rectal cancer and patients with medically uncontrolled ulcerative colitis $[5,6]$. This report documents the use of the same method in two patients with CD-related RVF and rectal stenosis.

\section{Case presentation \\ Patients}

A 22-year old woman was diagnosed with colonic CD 6 years earlier. For 4 years, she experienced fluctuating disease, with periods of remission and recurrence. She was initially treated with maximal doses of 5aminosalicylate (5-ASA), and corticosteroids, but later switched doses to azathioprine. Two years earlier, she started to pass gas from her vagina, and she was diagnosed with RVF due to CD. She was started on induction therapy using infliximab, but her symptoms did not improve. She also had a 2-year history of intestinal obstruction due to $\mathrm{CD}$-associated rectal stenosis. She underwent endoscopic balloon dilatation to treat the stenosis, but experienced no improvement. Because of her inability to take nutrition through her intestinal tract, she was started on total parenteral nutrition. She consulted our department for the treatment of RVF and repeat intestinal obstruction. A lower gastrointestinal series showed the disappearance of haustra, along with stenosis in the transverse and descending colon (Fig. 1a), rectal stenosis and RVF (Fig. 1b). Dual-port laparoscopic abdominoperineal resection, from the transverse colon near the splenic flexure to the rectum, was performed. The resected specimen showed both the RVF and rectal stenosis (Fig. 2). The patient experienced no perioperative or postoperative complications. She was discharged 14 days after surgery and has not experienced any recurrence of $C D$ for 3 years.

A 33-year old woman was diagnosed with small intestinal and colonic CD 14 years earlier. Six years ago, she underwent ileocecal resection for stenosis of the ileum. After surgery, she was started on infliximab but had to discontinue treatment because of the side effects of that drug. Three years ago, she started to pass gas from her vagina, and she was diagnosed with RVF due to CD. Medical therapy was unsuccessful, and she consulted our department. A preoperative lower gastrointestinal series showed the RVF, along with stenosis and the disappearance of haustra in the transverse and descending colon. She underwent the same operation as the first patient, with the same extent of resection. Pathological examination showed a fistula from the rectum to the vagina and stenosis from the transverse colon to the rectum. She did not experience any perioperative or
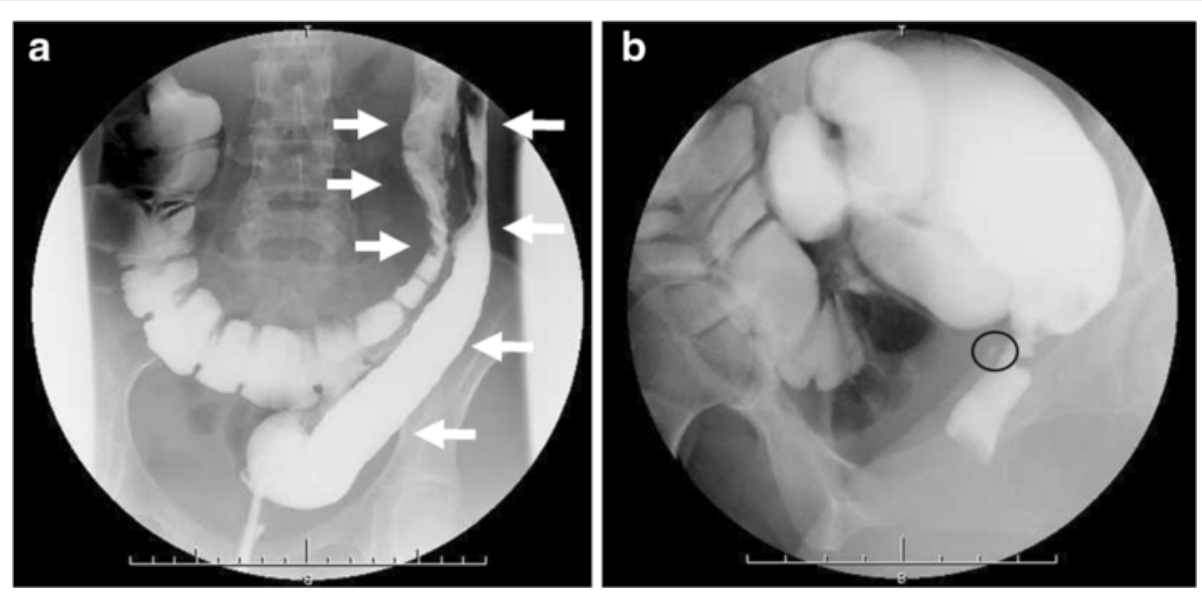

Fig. 1 Preoperative lower gastrointestinal series of patient 1, showing stenosis and the disappearance of haustra in the transverse and descending colon (white arrow in a) and the rectovaginal fistula (black circle in $\mathbf{b}$ ) 


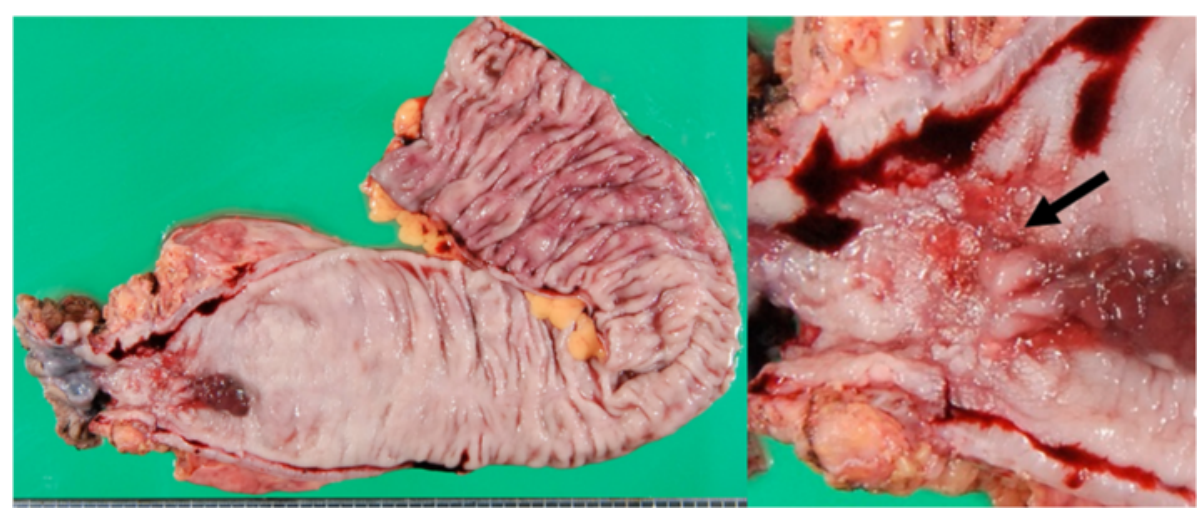

Fig. 2 View of the resected specimen from patient 2, showing a fistula from the rectum to the vagina (black arrow)

postoperative complications. She was discharged 15 days after surgery and has not experienced recurrence of CD for 4 years.

\section{Operative procedures}

A multichannel port was inserted through a $25-\mathrm{mm}$ skin incision in the right or left lower quadrant at the colostomy site. The colostomy site was determined by the preoperative marking, regardless of the surgical procedure. The choice of multichannel port site was based on the length of colon to be resected. An additional 5-mm

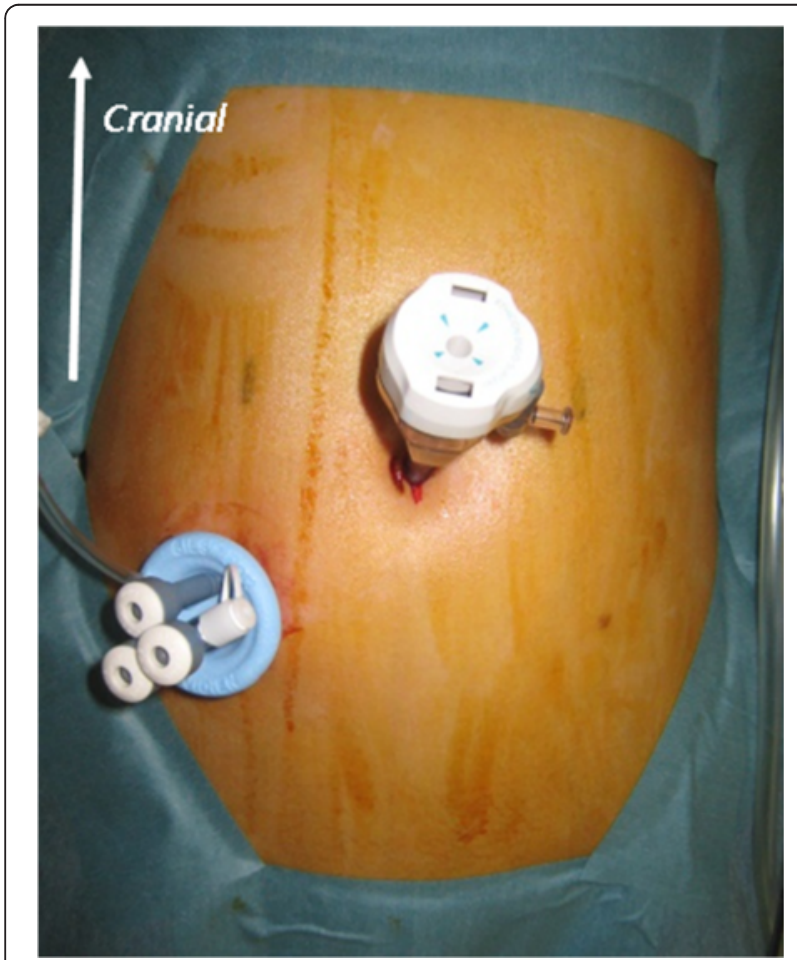

Fig. 3 Insertion of a multichannel port at the colostomy site through a $25-\mathrm{mm}$ skin incision in the right lower quadrant. A 5-mm trocar was inserted via the umbilicus trocar for the left hand was inserted at the umbilicus (Fig. 3). The surgeon and the assistant were positioned on the patient's right side (Fig. 4). For anterior dissection, the uterus was suspended by two stitches of 3-0 monofilament thread penetrating the left and right lower abdomen near the pubic bone. The assistant retracted the rectosigmoid ventrally using a curved grasper, and the peritoneum was incised using an ultrasonic coagulation incision device from the level of the sacral promontory to the base of the inferior mesenteric artery. After identification of the left ureter, the vascular pedicle was lifted vertically by the assistant. The inferior mesenteric artery was isolated and ligated $1 \mathrm{~cm}$ distal to the aorta. The inferior mesenteric vein was also ligated. Pelvic dissection was performed along the presacral avascular plane down to the pelvic floor and the top of the anal canal. The rectum was completely mobilized to the level of the levator ani muscle. The oral side of the intestine, which was free of the mucosal disorder due to $C D$, was cut off. Perineal dissection was performed circumferentially to the pelvic cavity. The specimen was retrieved through the perineal wound. A drain was placed from the umbilicus into the pelvic bottom, and a colostomy was fashioned at the site of the multichannel port (Fig. 5).

\section{Discussion}

This study reports the performance of dual-port laparoscopic abdominoperineal resection using a multiple port method. Neither patient experienced any perioperative or postoperative complications. In contrast, the rates of complications were reported to be much higher in patients with CD-related RVF who underwent conventional proctectomy, with $35 \%$ experiencing delayed perineal wound healing, $17 \%$ having intra-abdominal sepsis, and $15 \%$ experiencing stomal complications [7]. Another series reported delayed or failed perineal wound healing in almost $50 \%$ of patients [8]. The novel, minimally invasive procedure described here, dual-port 


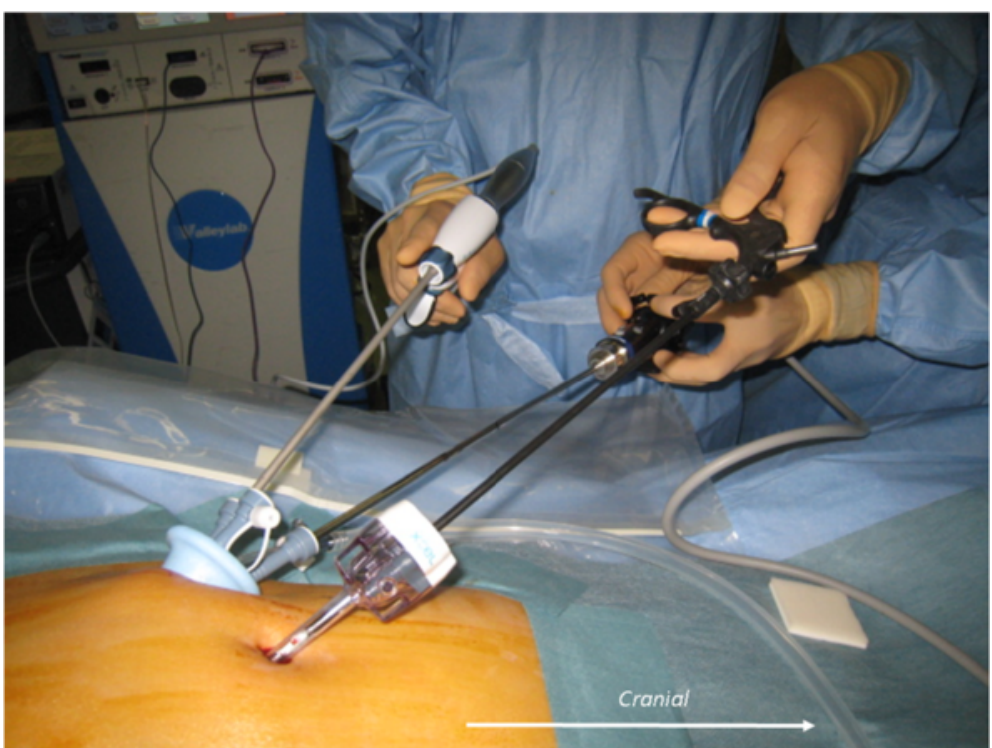

Fig. 4 Positioning of the surgeon and assistant on the patient's right side

laparoscopic abdominoperineal resection using a multiple port, has been found effective in patients with lower rectal cancer [5] and in patients with medically uncontrolled ulcerative colitis [6]. This procedure was completed successfully in all patients, without any

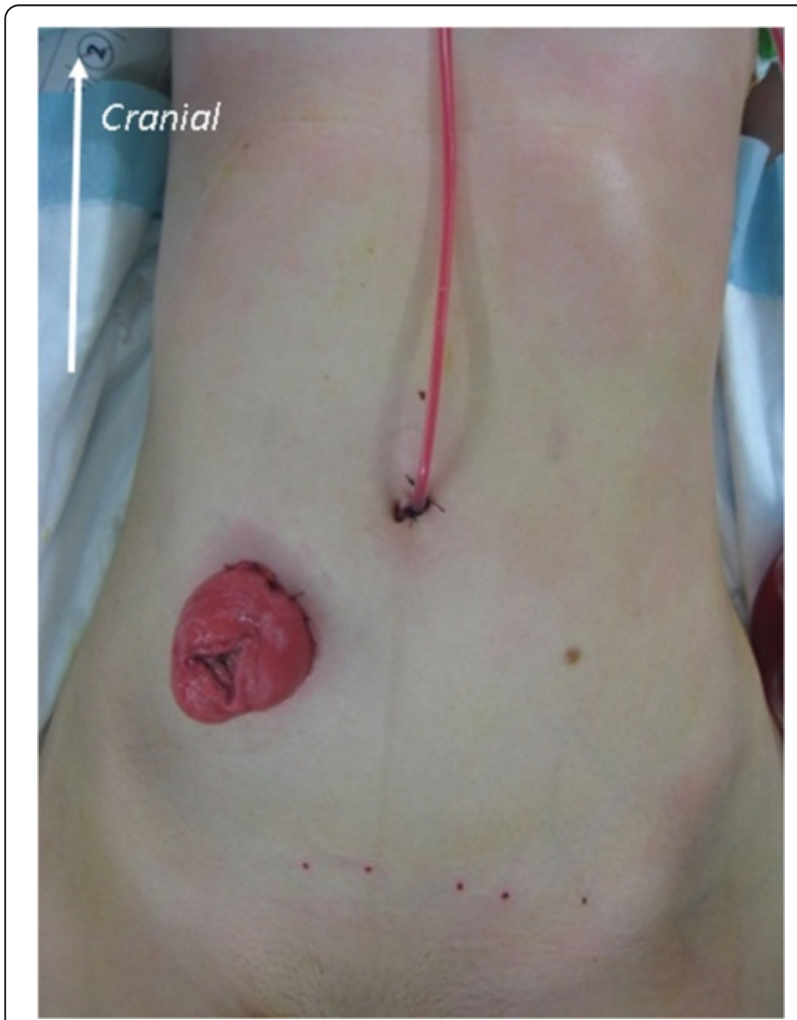

Fig. 5 Creation of a colostomy at the site of the multichannel port and placement of the drain through the umbilicus intraoperative complications, and all postoperative outcomes were satisfactory.

This report describes our use of this surgical method in two patients with CD-related RVF and rectal stenosis. The abdominal cavity was approached using two small incisions, with a multichannel port placed at the colostomy site through a $25-\mathrm{mm}$ skin incision in the lower quadrant and a 5-mm trocar inserted via the umbilicus for postoperative placement of a drainage tube. Neither patient experienced any intraoperative or postoperative complications. We recently reported that the postoperative neutrophil count was lower after SLIS +1 port laparoscopy-assisted than after conventional laparoscopy-assisted anterior resection for rectal cancer [4]. Furthermore, the former group experienced a significant difference in body temperature on postoperative day 1 , indicating a lower degree of inflammation. Our findings suggest that this procedure, involving small incisions and minimal invasiveness, may reduce the risk of complications and benefit not only patients with rectal cancer and ulcerative colitis but also patients with CD-related RVF and rectal stenosis.

$\mathrm{CD}$ is the second most common cause of RVF after obstetrical trauma. The incidence of RVF in women with CD is approximately $3-10 \%$. RVF may cause significant clinical distress and social embarrassment. RVFs are extremely difficult to close medically [9], often leaving surgery as the only option [10]. Medical treatments have included antibiotics, corticosteroids, and immunosuppressants, but these agents are associated with low rates of long-term symptom control and unacceptably high rates of recurrence [11]. Infliximab, a monoclonal 
antibody to tumor necrosis- $\alpha$ (TNF- $\alpha$ ), is a major advance in the treatment of fistulizing $\mathrm{CD}$ disease and has completely altered treatment strategies for perianal disease [12]. However, analysis of the results of the ACCENT II (A CD Clinical trial Evaluating infliximab in a New long-term Treatment regimen in patients with fistulizing $\mathrm{CD}$ ) trial found that $56 \%$ of patients on maintenance therapy with infliximab experienced RVF recurrence [10]. Another study showed that response to infliximab differed among patients with different types of CD fistula [13]. The closure rate after 4 to 6 weeks of treatment was $76 \%$ for all external CD fistulas, but only $14 \%$ for CD-associated RVF [13].

Patients who cannot be managed medically or are resistant or intolerant to infliximab can be managed surgically. Proctectomy was performed initially because of the high recurrence rate of CD-related RVF and difficulties treating rectal stenosis. To date, there have been no prospective, randomized, controlled trials assessing methods for the surgical correction of CD-related RVF [14]. Transvaginal, perineal, and transanal approaches, with or without transabdominal mobilization, can be used for local repair. Fecal diversion remains a problem, but protecting the fistula repair with a diverting stoma was reported to improve healing and reduce recurrence [15]. However, even with a diverting stoma, the cure rate remains less than satisfactory. The rates of recurrence of CD-related RVF have been reported to range from 25 to $50 \%$, higher than the recurrence rates of other $\mathrm{CD}$ fistulas [16-20]. Furthermore, most studies have considered only short-term outcomes. For example, of 12 patients with CD-related RVF who underwent local repairs, 7 (58 \%) showed recurrence [16]. Proctectomy is still considered the only radical cure for Crohn's-related RVF.

Both patients in this report presented with RVF and rectal stenosis, with the latter causing repeat intestinal obstruction. Rectal strictures due to $\mathrm{CD}$ are as difficult to treat as RVF. For example, $66 \%$ of patients with perianal $\mathrm{CD}$ and rectal strictures required a permanent stoma, with multivariate analysis showing that rectal stricture was independently predictive of the need for a permanent stoma [3].

This report has certain limitations. First, both patients had low degrees of adhesion, allowing conventional laparoscopic surgery. Second, this operation required high operative skill of the entire surgical team. The surgeon and team in this study had experience with over 500 laparoscopic colorectal resection procedures, including reduced port surgery for colorectal diseases including colorectal cancer.

\section{Conclusions}

CD-related RVF and rectal stenosis are difficult to manage medically and surgically. Dual-port laparoscopic abdominoperineal resection using a multichannel port, when performed by experienced surgeons, may be useful for selected patients with these conditions.

\section{Consent}

Written informed consent was obtained from both patients for publication of this case report and any accompanying images. A copy of the written consent is available for review by the Editor-in-Chief of this journal.

\section{Acknowledgments \\ We thank the staff of Hokkaido University Hospital.}

\section{Authors' contributions}

$\mathrm{SH}, \mathrm{TS}, \mathrm{HS}, \mathrm{NT}$, and HK participated in the care of the patients. All authors participated in data collection. FM and SH evaluate these two patients based on previous literature and drafted the manuscript. NT and AT participated in revising the manuscript critically. All authors read and approved the final manuscript.

\section{Authors' information}

FM is a doctoral student; SH, TY, SS, NM, TS, HS, HK, and NT are staff surgeons; and AT is a professor in the Department of Gastroenterological Surgery I of Hokkaido University Graduate School of Medicine.

\section{Competing interests}

The authors declare that they have no competing interests.

Received: 18 March 2016 Accepted: 4 August 2016

Published online: 27 August 2016

\section{References}

1. Levy C, Tremaine WJ. Management of internal fistulas in Crohn's disease. Inflamm Bowel Dis. 2002;8:106-11.

2. Schwartz DA, Loftus Jr EV, Tremaine WJ, Panaccione R, Harmsen WS, Zinsmeister AR, et al. The natural history of fistulizing Crohn's disease in Olmsted County, Minnesota. Gastroenterology. 2002;122:875-80.

3. Galandiuk S, Kimberling J, Al-Mishlab TG, Stromberg AJ. Perianal Crohn disease: predictors of need for permanent diversion. Ann Surg. 2005; 241:796-802.

4. Kawamata F, Homma S, Minagawa N, Kawamura H, Takahashi N, Taketomi A. Comparison of single-incision plus one additional port laparoscopyassisted anterior resection with conventional laparoscopy-assisted anterior resection for rectal cancer. World J Surg. 2014;38:2716-23.

5. Ishikawa T, Homma S, Shibasaki S, Yoshida T, Minagawa N, Kawamura H, et al. Dual-port laparoscopic abdominoperineal resection using the intended stoma site as the multichannel port. Surg Today. 2015;45:1583-7.

6. Homma S, Kawamata F, Shibasaki S, Kawamura H, Takahashi N, Taketomi A. Does reduced-port laparoscopic surgery for medically uncontrolled ulcerative colitis do more harm than good? Asian J Endosc Surg. 2016:9:24-31.

7. Yamamoto T, Allan RN, Keighley MR. Audit of single-stage proctocolectomy for Crohn's disease: postoperative complications and recurrence. Dis Colon Rectum. 2000;43:249-56.

8. Cohen JL, Stricker JW, Schoetz Jr DJ, Coller JA, Veidenheimer MC Rectovaginal fistula in Crohn's disease. Dis Colon Rectum. 1989;32:825-8.

9. Present DH, Rutgeerts P, Targan S, Hanauer SB, Mayer L, van Hogezand RA, et al. Infliximab for the treatment of fistulas in patients with Crohn's disease. N Engl J Med. 1999;340:1398-405.

10. Sands BE, Blank MA, Patel K, van Deventer SJ. Long-term treatment of rectovaginal fistulas in Crohn's disease: response to infliximab in the ACCENT II Study. Clin Gastroenterol Hepatol. 2004;2:912-20.

11. Zhu YF, Tao GQ, Zhou N, Xiang C. Current treatment of rectovaginal fistula in Crohn's disease. World J Gastroenterol. 2011;17:963-7.

12. Ricart E, Panaccione R, Loftus EV, Tremaine WJ, Sandborn WJ. Infliximab for Crohn's disease in clinical practice at the Mayo Clinic: the first 100 patients. Am J Gastroenterol. 2001;96:722-9. 
13. Parsi MA, Lashner BA, Achkar JP, Connor JT, Brzezinski A. Type of fistula determines response to infliximab in patients with fistulous Crohn's disease. Am J Gastroenterol. 2004;99:445-9.

14. Hannaway CD, Hull TL. Current considerations in the management of rectovaginal fistula from Crohn's disease. Colorectal Dis. 2008;10:747-56.

15. Marchesa P, Hull TL, Fazio WW. Advancement sleeve flaps for treatment of severe perianal Crohn's disease. Br J Surg. 1998;85:1695-8.

16. Makowiec F, Jehle EC, Becker HD, Starlinger M. Clinical course after transanal advancement flap repair of perianal fistula in patients with Crohn's disease. Br J Surg. 1995;82:603-6.

17. Halverson AL, Hull TL, Fazio WW, Church J, Hammel J, Floruta C. Repair of recurrent rectovaginal fistulas. Surgery. 2001;130:753-8.

18. Joo JS, Weiss EG, Nogueras JJ, Wexner SD. Endorectal advancement flap in perianal Crohn's disease. Am Surg. 1998;64:147-50.

19. Ozuner G, Hull TL, Cartmill J, Fazio WW. Long-term analysis of the use of transanal rectal advancement flaps for complicated anorectal/vaginal fistulas. Dis Colon Rectum. 1996;39:10-4.

20. Sonoda T, Hull T, Piedmonte MR, Fazio WW. Outcomes of primary repair of anorectal and rectovaginal fistulas using the endorectal advancement flap. Dis Colon Rectum. 2002;45:1622-8.

\section{Submit your manuscript to a SpringerOpen ${ }^{\circ}$ journal and benefit from:}

- Convenient online submission

- Rigorous peer review

- Immediate publication on acceptance

- Open access: articles freely available online

- High visibility within the field

- Retaining the copyright to your article

Submit your next manuscript at $\gg$ springeropen.com 